Cite this article: Scott P. Exploiting the information revolution: call for independent evaluation of the latest English national experiment.

J Innov Health Inform. 2015;22(1):244-249.

http://dx.doi.org/10.14236/jhi.v22i1.139

Copyright (C 2015 The Author(s). Published by BCS, The Chartered Institute for IT under Creative Commons license http://creativecommons.org/ licenses/by/4.0/

Author address for correspondence:

Philip Scott

Senior Lecturer

Centre for Healthcare Modelling and Informatics School of Computing, University of Portsmouth Portsmouth, UK

Email: philip.scott@port.ac.uk

Accepted January 2015

\section{Exploiting the information revolution: call for independent evaluation of the latest English national experiment}

\author{
Philip Scott \\ Centre for Healthcare Modelling and Informatics, School of Computing, University of Portsmouth, \\ Portsmouth, UK
}

\begin{abstract}
Background The English National Health Service (NHS) has a long history of national experiments with information technology; some successful, others less so. The NHS England Five Year Forward View aspires to 'Exploit the information revolution' through the transformational work of the National Information Board (NIB). NIB has published a 'Framework for Action' that promotes citizen empowerment, information availability, transparency, public trust, innovation, informatics skills and societal value.

Issue The framework sets out many laudable and common sense ambitions, but is light on evidence to support its aspirations, or plans for its evaluation. Considerable resource was invested in evaluation studies in the later stages of the National Programme for IT in England, but the analyses do not seem to have been included. Most of the cited evidence is from an unpublished report by management consultants rather than independent peer-reviewed work.

Recommendation National experiments of this importance should be evidence based and properly evaluated so that each iteration of 'information revolution' produces an evidence base to inform subsequent generations of care provision models and technology innovation. Evaluation should be planned from the very start rather than added in as an afterthought. Like any good business plan there should be defined critical success factors for health and social care, and a declaration of how they might be measured. Unintended consequences should be qualitatively explored. Evaluation should also consider critical-interpretive social perspectives to understand the human factors in technology deployment and should seek a theoretically informed insight into the mechanisms of change.

Conclusions The NHS Five Year Forward View and the NIB framework set out challenging ambitions based on transformative use of information technology and collaborative partnerships with commissioners and providers. The framework stands up very well against the Hayes principles, but the learning opportunities associated with this programme should not be missed.
\end{abstract}

Keywords: evidence-based practice, health policy, medical informatics, programme evaluation 


\section{INTRODUCTION}

The NHS England Five Year Forward View ${ }^{1}$ aspires to 'Exploit the information revolution' through the transformational work of the National Information Board (NIB). The NIB has commendably brought together a broad spectrum of public and patient bodies and published a Framework for Action ${ }^{2}$ that sets out proposals based around citizen empowerment, information availability, transparency, public trust, innovation, informatics skills and societal value. These are all good aims, if not entirely new ones.

The NIB framework is keen to say that it is 'not a strategy' and 'not a national plan', but represents 'core and immediate priorities' that will be developed in a series of forthcoming 'roadmaps'. The framework and the associated NHS planning guidance ${ }^{3}$ do seem to reflect a genuine attempt at a more joined-up approach at the national level (in England) and a desire to build relationships with local commissioners and providers that are more open, collaborative and partnership based than previous central planning regimes have achieved. The framework also promises a published evidence base to support its proposals - one of the main points that this article addresses.

The framework is the latest in a long line of information strategies for the NHS in England (which it is, despite its protestations to the contrary) such as 'Implementing the infrastructure'4 in 1994, the seminal 'Information for Health'5 in 1998, the well intentioned but ultimately doomed 'Delivering 21st Century Support for the NHS' 6 in 2002 and the information Revolution'7 consultation that led to the 2012 (but already archived) 'Power of Information' ${ }^{8}$ Each iteration has contributed something, but information strategies are transient by nature and have recurringly fallen short of their grander aims.

\section{ISSUE}

The framework sets out many laudable and common sense ambitions, but is light on evidence to support its aspirations, or plans for evaluating the results of its experimental interventions.

Considerable resource was invested in evaluation studies in the later stages of the National Programme for IT in England, but the analyses ${ }^{9}$ are not cited in the framework's reference lists. Most of the cited evidence is from an unpublished report by management consultants ${ }^{10}$ rather than independent peer-reviewed work. The consultancy report was 'commissioned to support this framework', which inevitably raises questions about its objectivity. There is an 'Additional reference material' section that does give a bibliography of academic and grey literature relevant to each proposal heading, but it is not integrated into a coherent evidence-based justification. The only genuine evidence directly cited is the collection of research summaries produced by National Voices about person-centred care. ${ }^{11}$ However, the actual text of these digests is more nuanced than the rather sweeping generalisations offered by the framework and, curiously, this one good piece of evidence only merits a single incomplete sentence of comment (page 12, reference 14). ${ }^{2}$ Regrettably, the text of the framework does invite the suspicion of a selective use of knowledge from previously attempted 'revolutions'. The foreword promises that an evidence base will be published, but this only reinforces the inference that the proposals are primarily derived ideologically rather than evidentially.

Of course, there is a significant literature reporting various benefits of health information technology to clinicians, patients and management in a wide variety of settings, but systematic reviews have questioned the strength and sufficiency of the evidence base. ${ }^{12-14}$ Information technology can have negative impacts on care provision and patient outcomes, ${ }^{15-17}$ and there is a lack of mature measurement science in health informatics. ${ }^{18}$ The European Federation for Medical Informatics and International Medical Informatics Association working groups have provided sustained leadership to address these weaknesses and develop health informatics into a properly evidence-based discipline,${ }^{19}$ but this is a long journey from where we are now.

\section{RECOMMENDATION}

We first offer a brief critique of the main ideas of the framework, based around the questions.

- What is the evidence for the central assertions of the framework?

- What is planned for evaluation?

- How well does the framework apply the Hayes principles $^{20}$ ?

Two central assertions of the framework for health and social care in England are that:

1. information technology can reduce service consumption and operational costs; and

2. the desired 'information revolution' is feasible by 2020 . Given the massive funding gap ${ }^{21}$ facing care services, acknowledged in the forward view, it is understandably tempting to assume that information technology can make it all better and cheaper. However, previous generations of health service information strategies have had similar hopes.

\section{What is the evidence for the central assertions of the framework?}

\section{Reducing utilisation and costs}

The first fundamental assertion underpinning the whole argument of the framework is given in its foreword and repeated verbatim in the NHS England planning guidance:

'Technology can help people use care services less by supporting healthier lives and it can transform the cost of services when they are needed'.

\section{What evidence supports this claim?}

Under the heading: 'There is good evidence that better use of data and technology improves patient outcomes and the value of services', the document refers to:

1. an unpublished management consultancy report about potential benefits, according to its reported title;

2. anecdotal data from a US hospital; and

3. the National Voices evidence summaries. 
The latter sources cite systematic review evidence of reduced service consumption (in surgery) from improved pre-operative and pre-discharge information, conflicting results about telemonitoring and some evidence of the cost-effectiveness of home-based self-management (but with questions about its economic sustainability). ${ }^{22}$

Against this must be weighed other findings. For example the European Commission funded a study of the economic impact of interoperable electronic health records (EHRs) and electronic prescriptions (the 'EHR IMPACT' study). This 2010 report evaluated the costs and socio-economic benefits of EHRs in nine implementations in various European countries (including local, regional and national project of different kinds) and concluded that:

'EHRs and ePrescribing are beneficial socio-economic investments in better healthcare, but, except in very specific circumstances, need net cash injections'. ${ }^{23}$

So simply put, information technology makes things better but not cheaper.

Another obvious example is the large scale trial of telehealth in England, known as the whole system demonstrator (WSD). ${ }^{24}$ The WSD examined effects on mortality and secondary care utilisation, ${ }^{25}$ organisational issues, ${ }^{26}$ cost-effectiveness ${ }^{27,}{ }^{28}$ and the perceptions of healthcare professionals. ${ }^{29}$ The flagrant political spin on the findings of the WSD, as selectively exploited by the Department of Health, is well known. ${ }^{30}$ However, the plain fact is that the studies showed that telehealth was not cost effective, based on a realistic estimate of acceptable cost per qualityadjusted life year. Again, perhaps better but not cheaper.

In addition, there are sometimes new inefficiencies introduced by EHRs. The 2013 RAND Corporation report on physician satisfaction ${ }^{31,32}$ found that clinicians in thirty US practices agreed that EHRs improved communications, data access and some aspects of care quality. However, they mostly reported worsened satisfaction arising from time-consuming data entry, poorly designed user interfaces that did not match clinical workflow, interference with direct patient care, insufficient interoperability, information overload, cost, document templates and increased administrative tasks. These various inefficiencies (in some cases requiring work re-design to introduce a 'scribe' to support physician use of the EHR) are all tractable issues, but perhaps suggest that the current generation of off-the-shelf products may not pose a ready-made solution to health service transformation.

In another example, the effect of patient portals to promote self-management on service utilisation and efficiency is unclear; systematic reviews have reported mixed findings, whilst noting that a pronounced social and ethnic digital divide exists. ${ }^{14}$

There is no doubt that information technology has the potential to reduce transactional operating costs in many areas of health and social care, as in other industries, but the important questions are what will work in what circumstances and how well the transitional costs and operational changes will be managed. In many cases, the financial benefits are not likely to arise in the same organisational budget as the costs, so judicious whole-system management will be required.

\section{Feasibility by 2020}

The framework's second basic proposition is that an 'information revolution' by 2020 is feasible for health and social care in England. To support this, the framework uses the time-honoured analogies with simple transactional services like flight booking and online banking. While there are certainly 'customer transaction' elements in the administration of care (predominantly when it is elective), the long slog to make progress with even the easiest 'service channel' like hospital outpatient booking ${ }^{33,34}$ surely shows that even changing administrative transaction processes in the NHS is far from a trivial piece of business change - however, tantalisingly simple the technology may seem to be.

There are serious flaws in the banking and airline analogies. First, the inherent richness and density of patient information in all its forms is orders of magnitude more complex $^{35}$ than the simple data used in financial transactions or the instrumentation and logistics data used in aviation. Second, the finance and aviation companies have straightforward hierarchical management structures, unlike the fairly loose 'system' of autonomous professions and organisations that deliver health and social care in England. Third, both of the cited industries have had decades of sustained and substantial investment in their information technology capabilities. ${ }^{36,37}$

Of course, Wanless ${ }^{38}$ identified back in 2002 the very low proportionate spending on information technology in health as compared to other sectors of the UK economy. The most recent update $^{39}$ on NHS spending on information technology (not reported since 2009) did not show a significant improvement in revenue expenditure. It is unknown whether the selective capital financing provided through the NHS England technology funds ${ }^{40}$ has stimulated sustained increases in revenue expenditure. The successes of general practice computing in comparison to hospital EHRs had much to do with the incentives provided. ${ }^{41}$

No doubt many of the ambitions of the framework are eminently achievable. However, the briefly stated 2020 ambitions ('all care records digital, real-time, interoperable and using SNOMED CT') seem rather far-fetched. By way of comparison, using a relatively straightforward information requirement, the 'new' NHS number was introduced in $1995^{4}$ yet is still not universally used after nearly 20 years (as acknowledged by the latest attempt to make it mandatory in the current planning guidance $^{3}$ ). Of course, 'stretch goals' are sometimes useful and no one would suggest an unnecessarily pessimistic or unambitious target. Perhaps the forthcoming 'roadmaps' will build confidence that the five year vision is achievable.

\section{What is planned for evaluation?}

With the notable exception of the experimental patient-controlled mobile care record (page 25), ${ }^{2}$ there is a lack of any evaluative framework that might identify either beneficial or harmful unintended consequences of this plan. Evaluation and prospective outcome measurement is only mentioned with reference to care data (page 34$)^{2}$ and in a passing reference to producing evidence of impact 'using experimental and quasiexperimental methods' (page 54). ${ }^{2}$ The digital maturity index (page 30$),{ }^{2}$ a 'census of digital progress', seems to be the 
principal measure of adoption and benefit. The planning guidance indicates that NHS England proposes to establish 'a new operational research and evaluation capability' (page 8,3.6), ${ }^{2}$ but this is for the new models of care not for the revolutionary information changes.

Policy makers and commissioners should want to ensure that national experiments of this scale and importance are properly evaluated so that each iteration of 'information revolution' produces an evidence base to inform subsequent generations of care provision models and technology innovation. Evaluation should be planned from the very start rather than added in as an afterthought. Like any good business plan there should be defined critical success factors for health and social care, and a declaration of how they might be measured. Unintended consequences should be qualitatively explored. Evaluation should consider critical-interpretive social perspectives ${ }^{42}$ to understand the human factors in technology deployment and should seek a theoretically informed insight into the mechanisms of change. ${ }^{43}$

\section{How well does the Framework apply the Hayes principles?}

This journal distilled the 2009 Hayes review ${ }^{44}$ into a set of ten guiding principles ${ }^{20}$ and proposed they could be used to evaluate plans for new information technology projects. Table 1 offers a high-level assessment of the framework using these 10 principles.

The framework stands up very well against the Hayes principles. Especially, in its patient-centric theme and its stated principles of subsidiarity, the approach is encouraging. On these criteria, as argued earlier, its notable weakness is on evaluation

Table 1 Assessing the framework against the Hayes principles ${ }^{20}$ (page references are to the framework ${ }^{2}$ )

\begin{tabular}{lll}
\hline Principles Comment & Assessment \\
\hline
\end{tabular}

Patient-centred principles

The patient must be at the centre of all information systems.

The provision of patient-level operational data should form the foundation - avoid the dataset mentality.

Excellent The framework is strongly patient centric and its theme is 'personalised care' for patients and citizens.

Good The objective (page 32) is 'collecting all the information required to support direct clinical care and the analytic needs of health and care, once and once only at the point of care', but datasets are needed until that is feasible.

Store health data as close to the patient as possible.

Less relevant

This principle set out how trust was key in sharing data. The closer physically data are held to the patient, the greater the willingness to share. Maybe less relevant in the age of the 'cloud'.

Enable the patient to take a more active role with their health data within a trusted doctor-patient relationship.

Excellent The self-management aim is fundamental to the framework.

\section{Subsidiarity principles}

Standardise centrally - patients must be able to benefit from interoperability.

Good

Provide a standard procurement package and an approved process that ensures safety standards and provision of interoperable systems.

Authorise a range of local suppliers so that health providers can select the system best meeting local needs.

Good

Allow local migration from legacy systems, as and when improved functionality for patients is available.

Good

Adopts the forward view idea of 'central standards, with explicit and extensive permissions to unleash local energy and enterprise' (page 13).

Good The framework leaves procurement to local decisions: 'we will be tight on standards and definitions, and clear on expectations regarding interoperability, but we will support local decision-making on systems, programmes, interfaces and applications... [local health and care communities will] decide upon and procure their own solutions, provided they meet nationally specified technical and professional standards' (page 17).

Proposes 'local buying consortia' and raises the possibility of replacing GPSoC with direct funding to allow greater freedom of choice of supplier (page 52).

This is implicit in the previous point.

\section{Strategic principles}

Evaluate health IT systems in terms of measureable benefits to patients.

Weak

Strategic planning of systems should reflect strategic goals for the health of patients/the population. 
(and using the evidence from previous evaluations). It is to be hoped that the forthcoming 'roadmaps' will address these issues.

\section{SUMMARY}

The NIB framework is a political programme, and therefore by its nature primarily a vehicle of ideology, but the NIB

\section{REFERENCES}

1. NHS England. NHS Five Year Forward View, 2014. Available from: http://www.england.nhs.uk/ourwork/futurenhs/.

2. National Information Board. Personalised Health and Care 2020: Using Data and Technology to Transform Outcomes for Patients and Citizens. A Framework for Action, 2014. Available from: https://www.gov.uk/government/publications/ personalised-health-and-care-2020.

3. NHS England. The Forward View into action: Planning for 2015/16, 2014. Available from: http://www.england.nhs.uk/wpcontent/uploads/2014/12/forward-view-plning.pdf.

4. Information Management Group. Implementing the Infrastructure for Information Management and Technology in the NHS: A Handbook for IM\&T Specialists. Leeds: NHS Executive, 1994.

5. Burns F. Information for Health, 1998. Available from: http:// webarchive.nationalarchives.gov.uk/20130107105354/http:// www.dh.gov.uk/prod_consum_dh/groups/dh_digitalassets/@ $\mathrm{dh} / @ e n /$ documents/digitalasset/dh_4014469.pdf.

6. UK Department of Health. Delivering 21st Century IT: Support for the NHS National Strategic Programme, 2002. Available from: http://webarchive.nationalarchives.gov.uk/20130107105354/ http://www.dh.gov.uk/prod_consum_dh/groups/dh_digitalassets/@dh/@en/documents/digitalasset/dh_4067112.pdf.

7. Department of Health. Liberating the NHS: An information revolution. A consultation on proposals, 2011. Available from: http:// webarchive.nationalarchives.gov.uk/20130107105354/http:// www.dh.gov.uk/prod_consum_dh/groups/dh_digitalassets/@ dh/@en/documents/digitalasset/dh_120598.pdf.

8. Department of Health. The power of information: giving people control of the health and care information they need, 2012. Available from: http://webarchive.nationalarchives.gov. uk/20130802094648/https://www.gov.uk/government/publications/giving-people-control-of-the-health-and-care-informationthey-need.

9. University of Birmingham. NHS Connecting for Health Evaluation Programme - Reports, 2014 [cited 2015 January 5]. Available from: http://www.birmingham.ac.uk/research/ activity/mds/projects/HaPS/PHEB/CFHEP/reports/reports. aspx.

10. McKinsey. Modelling the potential of digitally enabled processes, transparency and participation in the NHS. In paper.

11. National Voices. Prioritising person-centred care - the evidence, 2014 [cited 2015 January 5]. Available from: http://www. nationalvoices.org.uk/evidence. should seek guidance from published evidence and lessons from previous attempts. The NIB should positively welcome the idea of independent holistic evaluation so that success can be rightly commended and failure (inevitable in any innovation) can be learned from.

Once again we have an excellent opportunity to improve the evidence base for health and social care informatics. Let us hope the opportunity is not missed.

12. Black AD, Car J, Pagliari C, Anandan C, Cresswell K, Bokun $T$ et al. The impact of eHealth on the quality and safety of health care: a systematic overview. PLoS Medicine 2011;8(1):e1000387. http://dx.doi.org/10.1371/journal. pmed.1000387. PMid:21267058; PMCid:PMC3022523.

13. Garg AX, Adhikari NK, McDonald H, Rosas-Arellano MP, Devereaux PJ, Beyene $\mathrm{J}$ et al. Effects of computerized clinical decision support systems on practitioner performance and patient outcomes: a systematic review. Journal of the American Medical Association 2005;293(10):1223-38. http://dx.doi. org/10.1001/jama.293.10.1223. PMid:15755945.

14. Goldzweig CL, Orshansky G, Paige NM, Towfigh AA, Haggstrom DA, Miake-Lye I et al. Electronic patient portals: evidence on health outcomes, satisfaction, efficiency, and attitudes: a systematic review. Annals of Internal Medicine 2013;159(10):677-87. http://dx.doi.org/10.7326/0003-4819159-10-201311190-00006. PMid:24247673.

15. Han YY, Carcillo JA, Venkataraman ST, Clark RS, Watson RS, Nguyen TC et al. Unexpected increased mortality after implementation of a commercially sold computerized physician order entry system. Pediatrics 2005;116(6):1506-12. http://dx.doi. org/10.1542/peds.2005-1287. PMid:16322178.

16. Ammenwerth $E$ and Shaw NT. Bad health informatics can kill-is evaluation the answer? Methods of Information in Medicine 2005;44(1):1-3. PMid:15778787.

17. Cresswell KM, Bates DW and Sheikh A. Ten key considerations for the successful implementation and adoption of largescale health information technology. Journal of the American Medical Informatics Association 2013;20(e1):e9-13. http:// dx.doi.org/10.1136/amiajnl-2013-001684. PMid:23599226; PMCid:PMC3715363.

18. Scott PJ, Brown A, Friedman C, Wyatt J, Georgiou A and Eisenstein E. Improving the Science of Health Informatics by using Validated Instruments and Outcome Measures. Workshop presented at Medical Informatics Europe; Istanbul, Turkey; 2014.

19. Rigby M, Ammenwerth E, Beuscart-Zephir MC, Brender J, Hypponen $\mathrm{H}$, Melia $\mathrm{S}$ et al. Evidence based health informatics: 10 years of efforts to promote the principle. Joint contribution of IMIA WG EVAL and EFMI WG EVAL. Yearbook of Medical Informatics 2013;8(1):34-46. PMid:23974546.

20. de Lusignan $S$ and Krause P. The Hayes principles: learning from the national pilot of information technology and core generalisable theory in informatics. Informatics in Primary Care 2010;18(2):73-7. PMid:21078229. 
21. Nuffield Trust. A decade of austerity? The funding pressures facing the NHS from 2010/11 to 2021/22, 2012. Available from: http://www.nuffieldtrust.org.uk/publications/ decade-austerity-funding-pressures-facing-nhs.

22. Gaikwad R and Warren J. The role of home-based information and communications technology interventions in chronic disease management: a systematic literature review. Health Informatics Journal 2009;15(2):122-46.

23. Dobrev A, Jones $T$, Stroetmann V, Stroetmann $K$, Vatter $Y$ and Peng K. Interoperable eHealth is worth it: Securing benefits from Electronic Health Records and ePrescribing, 2010. Available from: https://ec.europa.eu/digital-agenda/en/news/interoperableehealth-worth-it-securing-benefits-ehrs-and-eprescribing.

24. Bower P, Cartwright M, Hirani SP, Barlow J, Hendy J, Knapp $M$ et al. A comprehensive evaluation of the impact of telemonitoring in patients with long-term conditions and social care needs: protocol for the whole systems demonstrator cluster randomised trial. BMC Health Services Research 2011;11:184. http://dx.doi.org/10.1186/1472-6963-11-184. PMid:21819569; PMCid:PMC3169462.

25. Steventon A, Bardsley M, Billings J, Dixon J, Doll H, Hirani S et al. Effect of telehealth on use of secondary care and mortality: findings from the Whole System Demonstrator cluster randomised trial. British Medical Journal 2012;344:e3874. http://dx.doi.org/10.1136/bmj.e3874. PMid:22723612; PMCid:PMC3381047.

26. Hendy J, Chrysanthaki T, Barlow J, Knapp M, Rogers A, Sanders $C$ et al. An organisational analysis of the implementation of telecare and telehealth: the whole systems demonstrator. BMC Health Services Research 2012;12:403. http:// dx.doi.org/10.1186/1472-6963-12-403. PMid:23153014; PMCid:PMC3532839.

27. Henderson C, Knapp M, Fernandez JL, Beecham J, Hirani $\mathrm{SP}$, Beynon $\mathrm{M}$ et al. Cost-effectiveness of telecare for people with social care needs: the whole systems demonstrator cluster randomised trial. Age and Ageing 2014;43(6):794-800. http://dx.doi.org/10.1093/ageing/afu067. PMid:24950690; PMCid:PMC4204660.

28. Henderson C, Knapp M, Fernandez JL, Beecham J, Hirani SP, Cartwright $\mathrm{M}$ et al. Cost effectiveness of telehealth for patients with long term conditions (whole systems demonstrator telehealth questionnaire study): nested economic evaluation in a pragmatic, cluster randomised controlled trial. British Medical Journal 2013;346:f1035. http://dx.doi.org/10.1136/bmj.f1035. PMid:23520339.

29. MacNeill V, Sanders C, Fitzpatrick R, Hendy J, Barlow J, Knapp M et al. Experiences of front-line health professionals in the delivery of telehealth: a qualitative study. The British Journal of General Practice 2014;64(624):e401-7. http://dx.doi.org/10.3399/ bjgp14X680485. PMID:24982492; PMCID:PMC4073725.

30. Greenhalgh T. Whole System Demonstrator trial: policy, politics, and publication ethics. British Medical Journal 2012;345:e5280. http://dx.doi.org/10.1136/bmj.e5280. PMID: 22868961.
31. RAND Corporation. Factors Affecting Physician Professional Satisfaction and Their Implications for Patient Care, Health Systems, and Health Policy, 2013. Available from: http://www. rand.org/content/dam/rand/pubs/research_reports/RR400/ RR439/RAND_RR439.pdf. PMid:17877873.

32. Drummond D. 9 Reasons Physicians Hate EMR - The 2013 RAND Study, 2013 [cited 2015 January 5]. Available from: http://www.thehappymd.com/blog/bid/351428/9-Reasons-Physicians-Hate-EMR-The-2013-RAND-Study.

33. Rashid M, Abeysundra L, Mohd-Isa A, Khan $Y$ and Sismeiro $C$. Two years and 196 million pounds later: where is Choose and Book? Informatics in Primary Care 2007;15(2):111-9.

34. Greenhalgh T, Stones R and Swinglehurst D. Choose and Book: a sociological analysis of 'resistance' to an expert system. Social Science \& Medicine 2014;104:210-9. Epub 2014/03/04 http://dx.doi.org/10.1016/j.socscimed.2013.12.014.

35. Beale T. The health record: why is it so hard? Haux $R$ and Kulikowski C (Eds). IMIA Yearbook of Medical Informatics 2005. Stuttgart: Schattauer; 2005, pp. 301-4.

36. Copeland D and McKenney J. Airline reservations systems: lessons from history. MIS Quarterly 1988;12(3):353-70. http:// dx.doi.org/10.2307/249202.

37. Scott $S$ and Zachariadis M. Origins and development of SWIFT, 1973-2009. Business History 2012;54(3):462-82. http://dx.doi. org/10.1080/00076791.2011.638502.

38. Wanless D. Securing Our Future Health: Taking a Long-Term View, 2002. Available from: http://webarchive.nationalarchives. gov.uk/20130129110402/http://www.hm-treasury.gov.uk/consult_wanless_final.htm.

39. NHS Connecting for Health. NHS IM\&T Investment Survey, 2009. Available from: http://webarchive.nationalarchives.gov. uk/20130502102046/http://www.connectingforhealth.nhs.uk/ resources/imtstaff/2009summaryresults.pdf.

40. NHS England. The Integrated Digital Care Technology Fund, 2014 [cited 2015 January 12]. Available from: http://www.england.nhs.uk/ourwork/tsd/sst/tech-fund/.

41. Benson T. Why general practitioners use computers and hospital doctors do not--Part 1: incentives. British Medical Journal 2002;325(7372):1086-9. PubMed PMID: 12424171. http://dx.doi.org/10.1136/bmj.325.7372.1090. http:// dx.doi.org/10.1136/bmj.325.7372.1086. PMid:12424171; PMCid:PMC131190.

42. Greenhalgh $T$ and Russell J. Why do evaluations of eHealth programs fail? An alternative set of guiding principles. PLoS Medicine 2010;7(11):e1000360. http://dx.doi.org/10.1371/journal.pmed.1000360. PMid:21072245; PMCid:PMC2970573.

43. De Silva MJ, Breuer E, Lee L, Asher L, Chowdhary N, Lund C et al. Theory of change: a theory-driven approach to enhance the Medical Research Council's framework for complex interventions. Trials 2014;15.

44. Hayes G. The NHS information technology (IT) and social care review 2009: a synopsis. Informatics in Primary Care 2010;18(2):81-8. PMid:21078230. 